\title{
Substratos no enraizamento de estacas de noni
}

\section{Substrates in Morinda citrifolia staces rooting}

\author{
Marcus Vinicius Sandoval Paixão ${ }^{1}$, Caroline Merlo Meneghelli ${ }^{2}$,Lorena Aparecida Merlo Meneghelli ${ }^{3}$, Leidiane Zinger ${ }^{4}$, \\ Gleides Pulcheira Paixão
}

Resumo: O noni (Morinda citrifolia L.) é pertencente à família Rubiaceae, cresce extensivamente entre as ilhas do Pacífico, sendo considerada uma das mais significantes plantas da medicina tradicional dessas comunidades. Sua introdução se deu há poucos anos e, devido a isto, ainda não há material propagativo suficiente para o cultivo em escala comercial, porém, nas últimas décadas, observou-se um aumento significativo do interesse comercial em relação aos produtos contendo essa planta, principalmente o suco das frutas do noni. Objetivou-se avaliar diferentes substratos no enraizamento de estacas de noni. O experimento foi conduzido no viveiro de produção de mudas, no Instituto Federal do Espírito Santo. Foram utilizadas estacas de talão, colhidas em plantas adultas de noni com $20 \mathrm{~cm}$ de comprimento, e colocadas para enraizar em tubetes $290 \mathrm{~mL}$, nos substratos: terra, areia, bioplant ${ }^{\circledR}$ e vermiculita. O delineamento foi inteiramente casualizado, com cinco repetições de doze estacas, sendo avaliados após 120 dias as variáveis: sobrevivência das estacas; número de folhas; diâmetro do coleto; comprimento da raiz; volume de raízes; massa verde raiz; massa verde folhas; massa seca raiz e massa seca folhas. O substrato terra mostrou-se superior aos outros substratos, sendo recomendado o transplante precoce de estacas de noni enraizadas em tubetes.

Palavras chave: Morinda citrifolia; Propagação vegetativa; Estaquia.

Abstract: The noni (Morinda citrifolia L.) belongs to the Rubiaceae family, growing extensively among the Pacific islands, being considered one of the most significant traditional medicine plants of these communities. Its introduction occurred only a few years ago, and because of this, there is still not enough propagating material for cultivation on a commercial scale, but in the last decades there has been a significant increase in commercial interest in relation to the products containing this plant, mainly the juice of noni fruits. The objective of this study was to evaluate different substrates in the rooting of noni cuttings. The experiment was conducted at the seedling nursery at the Federal Institute of Espírito Santo. Beech cuttings were harvested in $20 \mathrm{~cm}$ long noni adult plants and placed in $290 \mathrm{~mL}$ tubing on substrates: soil, sand, bioplant ${ }^{\circledR}$ and vermiculite. The design was completely randomized, with five replications of twelve stakes, being evaluated after 120 days the variables: survival of the stakes; number of leaves; collecting diameter; root length; volume of roots; root green mass; green leaves; dry mass root and dry mass leaves. The soil substrate showed to be superior to the other substrates, being recommended the early transplant of noni cuttings rooted in tubes.

Keywords: Morinda citrifolia; Vegetative propagation; Cutting.

\footnotetext{
*Autor para correspondência

Recebido para publicação em 12/03/2017; aprovado em 08/09/2017

${ }^{1}$ Professor DSc., Instituto Federal do Espírito Santo, Campus Santa Teresa, e-mail: mvspaixao@bol.com.br

${ }^{2}$ Mestre em produção vegetal, Instituto Federal do Espírito Santo, Campus Santa Teresa, e-mail: carol.merlo@hotmail.com;

${ }^{3}$ Engenheira Agrônoma, Instituto Federal do Espírito Santo, Campus Santa Teresa, e-mail: lorena.merlo@ hotmail.com,

${ }^{4}$ Engenheira Agrônoma, Instituto Federal do Espírito Santo, Campus Santa Teresa, e-mail: leidi.zinger@ hotmail.com,

${ }^{5}$ Professora DSc., Instituto Federal do Espírito Santo, Campus Santa Teresa, e-mail: gleidespaixao@bol.com.br
} 


\section{INTRODUÇÃO}

O noni (Morinda citrifolia L.) é pertencente à família Rubiaceae, cresce extensivamente entre as ilhas do Pacífico, sendo considerada uma das mais significantes plantas da medicina tradicional dessas comunidades (BASAR et al., 2010). A planta é uma frutífera exótica e fornece matériaprima de valor comercial pelas suas propriedades benéficas relacionadas ao consumo humano (SILVA, et al., 2009).

A espécie é um arbusto perene com altura variando de 3 a 10 metros, originária de clima tropical e subtropical. Apresenta tronco ereto, folha grande de coloração verde brilhante e formato elíptico, com flores brancas tubulares. Mesmo existindo vários relatos de plantio em vários estados do Brasil, como Pará, Acre, São Paulo, Minas Gerais, entre outros, o cultivo do noni em escala comercial ainda é muito restrito.

Sua introdução se deu na década passada, devido a isto, ainda não existe material propagativo suficiente para abastecer o cultivo em larga escala, porém, nos últimos anos, observou-se um aumento significativo do interesse comercial em relação aos produtos contendo essa planta, principalmente o suco dos frutos do noni (SILVA et al., 2012).

Apesar do grande sucesso e demanda internacional pelos produtos do noni, principalmente o suco dos frutos, no Brasil ainda são poucos os trabalhos de pesquisa desenvolvidos com essa espécie, sendo escassas as informações referentes às características agronômicas, como a forma mais adequada de propagação, espaçamento, manejo, formação de mudas, entre outras, sem as quais dificulta a condução do cultivo, ocorrendo a redução da qualidade e rentabilidade econômica (SOUSA et. al., 2009).

A cultura do noni pode ser propagada de forma sexuada (sementes) ou assexuada (estacas). Segundo Leite et al. (2012) a principal desvantagem da propagação por sementes é que, sem tratamento de sementes ou condições ambientais desfavoráveis, a uniformidade da germinação das sementes pode ser comprometida e na produção de mudas pode ter a germinação tardia prolongando o período para o transplante, em contrapartida a propagação por estacas promove a obtenção de, mudas precoces por superar o período de juvenilidade.

A escolha do substrato é de fundamental importância, pois é onde o sistema radicular irá desenvolverse, determinando o crescimento da parte aérea até o momento do transplante. Este substrato deve ser isento de patógenos, possuir bom equilíbrio entre macro e microporos, boa fertilidade para um bom desenvolvimento radicular, capacidade de retenção de água e consistência visando à obtenção de torrões intactos quando retirados do recipiente, baixo custo e fácil obtenção (JABUR; MARTINS, 2002).

O substrato é determinante no desenvolvimento sadio das mudas, uma vez que é a primeira fonte nutritiva e qualquer mudança na sua composição pode alterar a formação das plantas. A função do substrato é servir de suporte estrutural para as plantas, além de fornecer água e nutrientes (FERREIRA et al., 2009; FERMINO et al., 2010).

O tipo de substrato, volume do recipiente, irrigação, fertilização adequada e gestão da produção proporcionam condições para a obtenção de plantas com alta qualidade para garantir o sucesso no campo (COSTA et al., 2012). Mudas com padrão de qualidade adequada apresentam condições propícias de crescimento e de competição por fatores externos como água, luz e nutrientes (CARON et al., 2010).

Dentre os diversos fatores essenciais no desenvolvimento da muda, o substrato a ser utilizado pode ser considerado como de extrema importância, existindo substratos comerciais, com formulações especificas e culturas recomendadas e substratos que são preparados pelo próprio produtor com base na literatura existente e materiais disponíveis na propriedade. Possui a finalidade de sustentar a muda e fornecer condições adequadas para o crescimento e funcionamento do sistema radicular, assim como os nutrientes necessários ao crescimento da muda, devendo ser isento de sementes de plantas invasoras, pragas e patógenos em geral (HARTMANN et al., 2011)

O presente trabalho teve como objetivo avaliar o efeito de diferentes substratos no enraizamento de estacas de noni (Morinda citrifolia L.).

\section{MATERIAL E MÉTODOS}

O experimento foi conduzido no viveiro de produção de mudas, tela de poliolefina com 50\% de sombreamento, localizado no setor de viveiricultura do Instituto Federal do Espírito Santo (IFES-Campus Santa Teresa), no período de janeiro a abril de 2015, localizado na Mesorregião Central Espírito-Santense, cidade de Santa Teresa-ES (1956'12'S e $40^{\circ} 35^{\prime} 28^{\prime}$ 'W), com altitude de $155 \mathrm{~m}$. O clima da região caracteriza-se como Cwa, mesotérmico, com estação seca no inverno e forte pluviosidade no verão (classificação de Köppen), com precipitação anual média de $1.404,2$ mm e temperatura média anual de $19,9^{\circ} \mathrm{C}$, com média máxima de $32,8{ }^{\circ} \mathrm{C}$ e mínima de $10,6{ }^{\circ} \mathrm{C}$ (INCAPER, 2011).

No experimento foram utilizadas estacas herbáceas e de talão, recém colhidas em plantas adultas de noni e colocadas para enraizar em tubetes $290 \mathrm{~mL}$, nos substratos: terra de barranco, areia, bioplant ${ }^{\circledR}$ e vermiculita.

O experimento foi preparado em delineamento inteiramente casualizado (DIC), com quatro substratos (tratamentos) e cinco repetições com 12 estacas cada.

Após 120 dias do estaqueamento, foram retiradas 10 estacas de cada tratamento e avaliou-se as seguintes variáveis: sobrevivência das estacas (SB); número de folhas (NF); diâmetro do coleto (DC) realizado com um paquímetro digital; comprimento da raiz (CR) medido com uma régua a partir do colo da planta até o último folíolo; volume de raízes (VR) utilizou-se um becker com aguá; massa verde da raiz (MVR); massa verde das folhas (MVF) utilizou-se uma balança de precisão; massa seca da raiz (MSR) e massa seca das folhas (MSF) com secagem em estufa $70^{\circ} \mathrm{C}$ por $72 \mathrm{~h}$. As irrigações foram feitas diariamente, utilizando-se microaspersores durante toda a condução do experimento, com três regas diárias às 8,12 e 16 horas, com duração de 15 minutos.

Os dados experimentais foram submetidos aos testes de Shapiro-Wilks $(\mathrm{p}>0,05)$, para verificação da normalidade e à análise de variância, sendo as médias de cada característica comparadas pelo teste de Tuckey em nível de 5\% de probabilidade com auxilio do programa $\mathrm{R}$.

\section{RESULTADOS E DISCUSSÃO}

De acordo com a tabela 1 , observa-se diferença entre os substratos utilizados nos parâmetros ligados a parte aérea, 
sobrevivência das estacas (SB), número de folhas (NF), massa verde das folhas (MVF), massa seca das folhas (MSF), o substrato terra mostrou-se superior aos outros substratos. Observa-se que para os parâmetros ligados a raiz, comprimento da raiz (CR), massa verde das raízes (MVR) e massa seca das raízes (MSR), não foi observado diferença, mostrando a efetividade de todos os substratos utilizados para estes parâmetros.

Os tubetes apresentam aeração maior que em canteiros, a forma geométrica e ranhuras em suas paredes internas condicionam crescimento radicular longitudinal maior, e este crescimento radicular é estimulado por condições de déficit hídrico (TAIZ; ZEIGER, 2012). Nestas condições, o sistema radicular pode apresentar menor acúmulo de matéria seca e volume, podendo justificar os dados coletados em relação aos tratamentos utilizados. Observa-se que não foi apresentada diferença estatística entre os tratamentos, para comprimento da raiz, massa verde da raiz e massa seca da raiz (Tabela 1).

Tabela 1. Valores médios de características no enraizamento de estacas de Noni (Morinda citrifolia L.) submetidos a diferentes substratos

\begin{tabular}{cccccccc}
\hline Tratamento & SB (\%) & NF & $\begin{array}{c}\text { CR } \\
(\mathrm{cm})\end{array}$ & MVR (mg) & $\begin{array}{c}\text { MVF } \\
(\mathrm{mg})\end{array}$ & $\begin{array}{c}\text { MSR (mg) } \\
(\mathrm{mg})\end{array}$ \\
\hline Areia & $75,1 \mathrm{~d}$ & $5,2 \mathrm{c}$ & $15,90 \mathrm{a}$ & $2085,4 \mathrm{a}$ & $1761 \mathrm{~b}$ & $255,8 \mathrm{a}$ & $599,2 \mathrm{~b}$ \\
Terra & $100 \mathrm{a}$ & $16,4 \mathrm{a}$ & $17,00 \mathrm{a}$ & $2893,8 \mathrm{a}$ & $3376,4 \mathrm{a}$ & $368,8 \mathrm{a}$ & $798,4 \mathrm{a}$ \\
Bioplant $^{\circledR}$ & $83,4 \mathrm{c}$ & $7,2 \mathrm{bc}$ & $16,84 \mathrm{a}$ & $2264,8 \mathrm{a}$ & $2673 \mathrm{ab}$ & $281,2 \mathrm{a}$ & $352 \mathrm{c}$ \\
Vermiculita $^{\text {CV } \%}$ & $91,6 \mathrm{~b}$ & $9,6 \mathrm{~b}$ & $16,72 \mathrm{a}$ & $2754,2 \mathrm{a}$ & $3406,4 \mathrm{a}$ & $321,0 \mathrm{a}$ & $621,2 \mathrm{ab}$ \\
\hline & 0 & 18,04 & 16,5 & 43,61 & 25,47 & 47,91 & 23,62 \\
\hline
\end{tabular}

Médias dos tratamentos para enraizamento, seguidas de mesma letra na coluna para cada variável, não diferem entre si pelo teste de Tukey em 5\% de probabilidade. $\mathrm{SB}=$ sobrevivência das estacas; $\mathrm{NF}=$ número de folhas; $\mathrm{CR}=$ comprimento da raiz; $\mathrm{MVR}=$ massa verde da raiz; $\mathrm{MVF}=$ massa verde das folhas; MSR = massa seca da raiz; MVR = massa seca das folhas .

Ainda em relação aos parâmetros ligados a raiz, embora os resultados obtidos não demonstrem diferença significativa entre eles, observa-se que o maior valor de comprimento de raiz, peso da matéria verde da raiz e peso da matéria seca das raízes foi encontrado quando utilizada a terra, podendo-se atribuir este resultado ao maior número e comprimento de raízes formadas nas estacas. Gonçalves e Minami (1994) observaram que a vermiculita propiciou grande desenvolvimento das raízes em estacas de calanchoe (Kalanchoe blossfeldiana 'Singapur'), tanto em comprimento como em volume, devido à grande capacidade de aeração e retenção de água. Observa-se que os resultados para a vermiculita aparecem próximos aos resultados para a terra.

Para os parâmetros que relacionam o crescimento da parte aérea, número de folhas (NF), massa verde das folhas (MVF) e massa seca das folhas (MSF), a terra e a vermiculita mostraram-se mais eficiente apresentando diferença significativa para o bioplant ${ }^{\circledR}$ e a areia, resultado que surpreende devido ao caráter orgânico encontrado no bioplant ${ }^{\circledR}$ porém esperado para a areia. A vermiculita só não foi equivalente a terra na sobrevivência e produção de folhas, fato que pode ser considerado à deficiência nutricional encontrado na vermiculita, principalmente o nitrogênio que possui grande influência na formação de folhas (Tab. 1). Para Garay et al. (2014) não há um substrato ideal, a escolha de um bom material depende das características da cultura e do custo para aquisição, tornando-se necessário testar diferentes substratos ou misturas de substratos para cada espécie. A vermiculita possui uma maior capacidade de retenção de água, mantendo desta forma, maiores valores para o teor de umidade na base das estacas e equilíbrio entre umidade e espaço de aeração, o que pode favorecer a formação de raízes (LIMA et al., 2013), sendo um dos mais utilizados para o enraizamento de estacas herbáceas e semi-lenhosas devido à elevada porosidade e boa retenção de umidade, pequena variação de características químicas e físicas, ser praticamente isenta de patógenos, plantas invasoras e insetos, e é encontrada facilmente em casas de comercialização de produtos agrícolas (HARTMANN et al., 2011).
A absorção ocorre de acordo com a retenção de agua retido pelo substrato e a absorção de água pela estaca está diretamente relacionada ao grau de contato entre esta e o filme de água ao redor das partículas do substrato, fato que pode ser considerado no desenvolvimento das estacas no substrato vermiculita.

Para as características ligadas a parte aérea, foi observada menor resposta da areia em relação aos parâmetros avaliados (Tab. 1). Dado semelhante foi encontrado por Moreira et al. (2015) trabalhando com mudas de guapuruvú, citando que o fato ocorreu possivelmente, por ser a areia um material inerte com baixa concentração de nutrientes, utilizado apenas para atividades específicas como cultivo fertirrigado. A avaliação realizada aos 60 dias após a emergência, o substrato areia, proporcionou o menor resultado para a variável altura de planta, evidenciando que este material não é indicado para a produção de mudas de guapuruvú. Provavelmente, a diferença foi ocasionada pelo menor número de folhas, que comprometeu a síntese de fotoassimilados para a planta.

Considerando o tipo de tubete utilizado na pesquisa, podemos relatar que o tempo de permanência da muda no tubete pode influenciar negativamente no desenvolvimento da muda. A reduzida quantidade de substrato pode acarretar na desnutrição, a partir de um ponto do desenvolvimento, quando é exigido um campo nutricional maior para que a muda continue com seu desenvolvimento normal, devendo a muda permanecer por tempo reduzido no tubete.

Os melhores resultados foram observados no substrato terra de barranco, com valores superiores para todos os parâmetros avaliados (Tab. 1). Este resultado pode ser explicado pela maior riqueza nutricional encontrada na terra em relação aos outros substratos utilizados na pesquisa.

Embora os solos apresentem diferenças em sua composição, a terra utilizada na pesquisa apresentou características satisfatórias em relação aos atributos químicos e físicos, de forma a apresentar resultados superiores aos substratos utilizados, proporcionando melhores resultados por apresentarem boas características físicas como equilíbrio entre o ar e a água, pela densidade adequada e pelo maior 
contato do substrato com a base da estaca favorecem o desenvolvimento das raízes adventícias.

Corroborando com a pesquisa, Miranda et al. (2003) obteve resultados expressivos em estacas de pessegueiro com a utilização de solo, as estacas enraizadas neste substrato obtiveram maior número médio de raízes primárias, apresentando uma média de 9,18 raízes por estaca, proporcionando maior percentual de estacas enraizadas e maior número de raízes formadas. Este resultado também pode ser explicado pelo fato de o solo utilizado ser do tipo areno-argiloso e possivelmente facilitaram a emissão e o desenvolvimento das raízes. Este autor considerou este como um substrato adequado para a propagação de pessegueiro.

\section{CONCLUSÃO}

O substrato terra de barranco apresentou-se como melhor substrato para produção de mudas de noni por estacas.

\section{REFERÊNCIAS}

BASAR, S.; UHLENHUT, T. K.; HOGGER, P.; SCHONE, F.; WESTENDORF, J. Analgesic and antiinflamatory activity of Morinda citrifolia L. (noni) fruit. Phytother Res. Institute of Experimental and Clinical Pharmacology and Toxicology, University Clinic Hamburg, Germany, v.24, n.1, p. 38-42, Jan. 2010.

CARON, B. O. SOUZA, V. Q. CANTARELLI, E. B. MANFORN, P. A. BEHLING. A. ELOY, E. Crescimento em viveiro de mudas de Schizolobium parahyba (vell.) S. F. Blake. Submetidas a níveis de sombreamento. Ciência Florestal, Santa Maria, v. 20, n. 4, p. 683-689, 2010.

COSTA, E.; OLIVEIRA, L. C. de. SANTO, T. L. do E. LEAL, P. A. M. Produção de mudas baruzeiro em diferentes ambientes e substratos protegidas. Engenharia Agrícola, Jaboticabal, v. 32, n.4, p. 633-641, 2012.

FERMINO, M. H.; GONÇALVES, R. S.; BATTISTIN, A.; SILVEIRA, J. R. P.; BUSNELLO, A. C.; TREVISAM, M. Aproveitamento dos resíduos da produção de conserva de palmito como substrato para plantas. Horticultura Brasileira, Brasília, v. 28, p. 282-286, 2010.

FERREIRA, M. G. R.; ROCHA, R. B.; GONÇALVES, E. P.; RIBEIRO, G. D. Influência do substrato no crescimento de mudas de cupuaçu (Theobroma grandiflorum Schum.), Acta Scientiarum Agronomy, v. 31, n. 4, p. 677-681, 2009.

GARAY, C. R. E.; BOGARIN, N. B. G.; OVIEDO, V. R. S. Producción de mudas de tomate en el sistema flotante. Investigación Agraria, v. 16, n. 2, p. 129-135, 2014.

GONÇALVES, A. L.; MINAMI, K. Efeito de substrato artificial no enraizamento de estacas de calanchoe (Kalanchoe x blossfeldiana cv. Singapur, Crassulaceae). Revista Scientia Agricola, Piracicaba, v. 51, n. 2, p. 240-244, 1994.

HARTMANN, H. T. KESTER, D. E. DAVIES JÚNIOR, F T. GENEVE, R. Plant propagation: principles and practices. 8th. ed. Boston: Prentice-Hall, 2011. 915p.
INCAPER. Planejamento e programação de ações para Santa Teresa. Programa de assistência técnica e extensão rural PROATER, Secretaria de Agricultura, 2011.

JABUR, M. A., MARTINS, A. B. G. Influência de substratos na formação dos porta-enxertos: limoeiro-cravo (Citrus limonia Osbeck) e tangerineira-cleópatra (Citrus reshni Hort. Ex Tanaka) em ambiente protegido. Revista Brasileira de Fruticultura, Jaboticabal v. 24, n. 2, p. 514-518. 2002.

LEITE, G. A.; CUNHA, L. F. M. M.; MEDEIROS, P. V. Q.; MENDONÇA, V. Superação de dormência de sementes de Noni. Revista Verde, Mossoró - RN, v. 7, n. 4, p. 120-128, out-dez, 2012.

LIMA, L. F.; RODRIGUES, A. J.; TORRES, R. A.; SOARES, N. S.; TAKANE, R. J. Efeito de diferentes substratos no enraizamento de estacas de Rhipsalis pilocarpa Loefgr. Cadernos de Agroecologia, v. 8, N. 2, Nov. 2013.

MIRANDA, C. S.; CHALFUN, N. N. J.; DUTRA, L. F.; HOFFMANN, A.; COELHO, G. V. de A. Enraizamento de estacas lenhosas de porta-enxertos para Pessegueiro. I. Umezeiro. Revista Brasileira Agrociência, v. 9, n. 3, p. 229232, jul-set, 2003.

MOREIRA, W. K. O.; ALVES, J. D. N.; LEÃO, F. A. N.; OLIVEIRA, S. S.; OKUMURA, R. S. Efeito de substratos no crescimento de mudas de guapuruvú (Schizolobium Parahyba (Vell.) S. F. Blake). Enciclopédia Biosfera, Centro Científico Conhecer - Goiânia, v.11 n.22; p. 1067, 2015.

SILVA, L. R.; MEDEIROS, P. V. Q.; LEITE G. A.; SILVA, K. J. P.; MENDONÇA, M.; SOUSA, J. L. Caracterização do fruto de noni (Morinda citrifolia L.). Horticultura Brasileira, v. 27, n. 02, p. S267-S271, 2009.

SILVA, L. R.; MEDEIROS, P. V. Q.; LEITE G. A.; SILVA, K. J. P.; MENDONÇA, M.; SOUSA, J. L.. Caracterização do fruto de Morinda citrifolia L. (noni). Revista Cubana de Plantas Medicinales, Ciudad de la Habana, v. 17, n. 1, p. 93100, mar. 2012.

SOUSA, J. A., NETO, P. A. F. S., FERREIRA, F. V. M., ARAUJO,D. B., SOUSA, J. C.R., AQUINO, A. R. L., SILVA, T. C., BEZERRA, F. C. Substrato para produção de mudas de noni (Morinda citrifolia). XXVI Congresso Brasileiro de Agronomia, Anais..., Gramados-RS, 2009.

TAIZ, L.; ZEIGER, E. Fisiologia vegetal. 4.ed. Porto Alegre: Artmed, 2012.819p. 